\title{
Arachnoiditis With Intrathecal \\ Morphine 12 Months Following \\ IMPLANTATION OF AN INTRATHECAL \\ Pump: A Case Report
}

Received: 2019-06-15

Accepted: 2019-08-22

Published: 2020-03-30

\author{
Avijit Sharma, MD \\ Kanishka Rajput, MD \\ Thomas Halaszynski, MD \\ Robert Chow, MD
}

\begin{abstract}
The utilization of intrathecal pumps is increasing as more practitioners are becoming familiar with their use, and as the applications of continuous intrathecal infusions increase. There are many potential risks with intrathecal pump implantation, which include the risk of infection, bleeding, nerve damage, as well as other potential issues. After prolonged usage, granuloma formation, medication tolerance, disease progression, mechanical failure, and arachnoiditis can also occur. Arachnoiditis has been associated with spinal disease, contrast media, preservatives in medications, infectious causes, hemorrhage, and more. The potential causes of arachnoiditis are many; however, it is infrequently associated with intrathecal pump infusates.

Morphine is commonly used in intrathecal pumps, either as a sole agent or in combination with other medications. Its role in arachnoiditis and catheter granuloma formation can be extrapolated from its effects on inflammation. In particular, it is well known that morphine causes mast cell activation and subsequent release of substance $P$ and tryptase. In addition, morphine can sensitize the central nervous system to inflammatory effects as it can enhance the release of substance $P$ from the dorsal root ganglia as well. Lastly, activation of $\mu$ receptors on lymphocytes can result in lymphocyte proliferation.

When arachnoiditis occurs in the setting of an intrathecal pump, there are several important considerations. These include the appropriate diagnosis of the cause as well as evaluation of potential treatment options. We report a case of intrathecal morphine-associated arachnoiditis that was diagnosed using both clinical and magnetic resonance imaging findings. This case describes a successful exchange of intrathecal morphine for intrathecal hydromorphone, with the subsequent improvement of the patient's symptoms of arachnoiditis.
\end{abstract}

Key words: Adhesive arachnoiditis, arachnoiditis, cancer pain, complications, intrathecal catheter, intrathecal drug delivery system, intrathecal hydromorphone, intrathecal inflammation, intrathecal morphine, intrathecal pump, intrathecal opioid, intrathecal ziconitide

From: Department of Anesthesiology, Yale University School of Medicine

Corresponding Author: Robert Chow, MD, Department of Anesthesiology, Yale University School of Medicine

E-mail: chow.robert@gmail.com

Conflict of Interest: None Declared

Disclaimer: There was no external funding in the preparation of this manuscript. Conflict of interest: Each author certifies that he or she, or a member of his or her immediate family, has no commercial association (i.e., consultancies, stock ownership, equity interest, patent/licensing arrangements, etc.) that might pose a conflict of interest in connection with the submitted manuscript. 


\section{BACKGROUND}

Implanted intrathecal (IT) drug delivery systems (IDDS) are widely used for both cancer and chronic non-cancer pain that has shown to be resistant to more conservative treatment modalities. IT medication administration can offer the benefits of reducing pain intensity while also decreasing the systemic side effects that can occur with high-dose oral opioids (i.e., drowsiness and confusion). The loss of clinical efficacy following IDDS implantation could be related to patient-related factors such as worsening/progression of the primary pain pathology, drug tolerance, obstruction of cerebral spinal fluid flow in the spinal canal, mechanical issues, or IT catheter tip occlusion from granuloma formation (1).

The use of highly concentrated narcotic and nonnarcotic analgesics has been associated with the formation of IT catheter granulomas. These are inflammatory masses at the tip of the IT catheter that can cause pain and/or neurologic dysfunction secondary to spinal cord compression (2-4). New-onset radicular pain with or without sensory and motor deficits in these patients should alert clinicians to the possibility of catheter granuloma formation. Magnetic resonance imaging (MRI) can often demonstrate the mass that has formed at the IT catheter tip. If the patient has no significant complaints or evidence of motor deficit/compromise, then the granuloma can be allowed to resolve on its own if the current therapy is discontinued or if a lower concentration of agent is administered. However, surgical exploration is indicated in the situation of an acute neurologic deficit secondary to neural compression.

IT catheter-associated masses are most frequently located at the catheter tip and often related to the opioid concentration within the IDDS as well as the absolute dose of IT opioid medication administered $(2,5)$. Arachnoiditis, however, is a rare complication associated with an implanted IDDS. Adhesive arachnoiditis (AA) is a clinical syndrome characterized by chronic inflammation and fibrosis, and sometimes associated with atrophy of the structures within the subarachnoid space. AA has also been related to contrast media used, trauma, surgery, medication containing preservatives, epidural steroids, localized infections, and local anesthetics. As an example, arachnoiditis has been reported following IT drug delivery of bupivacaine resulting in neurotoxicity, and in another situation involving a retained epidural Tuohy needle $(4,6)$.

A conclusive etiology of catheter-associated masses in patients receiving long-term IT analgesic therapy remains unclear, but several potential causes have been considered within the literature. Such examples have included preexisting anatomic dysfunction of neural tissues that could then be predisposed to additional neurologic analgesic toxicity, configuration of the IT catheter tip (7), pharmacodynamics of the medication(s) including dose and/or concentration $(5,7)$, infection, hypersensitivity reactions $(7,8)$, previous or simultaneous exposure to other intraspinal devices such as spinal cord stimulators (9), and flow dynamics of the regional cerebrospinal fluid (10).

It also remains possible that similar underlying pathophysiology (as described above) could be the etiology for the development of arachnoiditis from IT catheter placement in susceptible individuals. This case report describes a patient with cancer pain who had an IT pump implanted and who initially experienced great pain relief for around 8 months. Subsequently, the patient developed new-onset neurologic symptoms along with diminishing pain relief. A diagnosis of arachnoiditis was then made based on clinical findings and with MRI diagnostic testing. An outline of the management strategies conducted in this patient with this rare complication of arachnoiditis is detailed along with a brief review of the literature.

\section{CASE}

A 51-year-old male patient with a history of stage IV lung cancer was referred to our pain clinic for treatment of his cancer-related pain. Past medical history included chronic obstructive pulmonary disease, emphysema, coronary artery disease, hypertension, history of seizures, obstructive sleep apnea, asthma, and multiple deep venous thromboses. With the initiation of chemotherapy, the patient described a constant "total" body-burning pain with a rating of 4 out of 10 on the Numerical Rating Scale (NRS-11). The pain was not able to be managed with a multimodal analgesic therapy regimen consisting of $40 \mathrm{mg}$ of methadone daily, 800 $\mathrm{mg}$ of gabapentin 3 times a day, $60 \mathrm{mg}$ of duloxetine daily, and $30 \mathrm{mg}$ of oxycodone every 3 hours. Secondary to the patient's complaint of refractory pain, he was offered a trial consisting of an IT morphine infusion in order to evaluate his candidacy for implantation of a permanent IT pump.

During the trial period, an IT morphine infusion was initiated at $40 \mathrm{mcg}$ per hour while continuing the patient on his home methadone ( $40 \mathrm{mg}$ daily) to prevent withdrawal. The patient experienced significant pain relief (NRS-11 score 4 out of 10) and near resolution of his leg pain on postprocedure day 1 . The IT morphine in- 
fusion rate was increased to 50 mcg per hour for his complaint of residual back pain on postprocedure day 1 . The patient's pain continued to improve and he was able to progress to pain-free ambulation without requiring use of his cane. At the end of the trial period (3 days), the patient rated his NRS-11 pain score as 2 out of 10 .

The patient had surgical implantation of an IT pump 2 weeks following a successful trial. He was started on $1.2 \mathrm{mg}$ daily of IT preservative-free morphine that continued to provide great analgesic relief of his generalized pain and he was subsequently weaned off of all opioid medications over the next few weeks.

Over the next 8 months, the patient required an increase of his morphine infusion pump due to complaints of steadily increasing pain in the lower extremities. A timeline of the changing therapy is described and provided in Table 1. In addition, at the 8-month mark since implantation of the IT morphine pump, the patient reported crampy leg pain at 6 out of 10 and described the pain symptoms as being similar in quality to that experienced during the time he was diagnosed with a deep vein thrombosis (DVT). The morphine dose of the IT pump was yet again increased by $20 \%$ to $2.4 \mathrm{mg}$ per day with minimal pain relief of his initial symptoms. Due to increasing intensity of the pain along with radiation of pain into the legs, an MRI study was obtained. MRI of the thoracic and lumbar spine revealed new and different enhancement
Table 1. Timeline of changing therapy.

\begin{tabular}{|l|l|l|}
\hline Date & Dose Per Day & \% Increase \\
\hline $12 / 29 / 2017$ & Morphine $1.2 \mathrm{mg}$ & \\
\hline $2 / 6 / 2018$ & Morphine $1.439 \mathrm{mg}$ & 20 \\
\hline $4 / 17 / 2018$ & Morphine $1.726 \mathrm{mg}$ & 20 \\
\hline $6 / 13 / 2018$ & Morphine 1.89, PTM $0.095 \mathrm{mg}$ every $8 \mathrm{hrs}$ as needed & 10 \\
\hline $7 / 26 / 2018$ & Morphine $2 \mathrm{mg}$, PTM $0.1 \mathrm{mg}$ every $8 \mathrm{hrs}$ as needed & 6 \\
\hline 9/25/2018 & Morphine $2.2 \mathrm{mg}$, PTM $0.1 \mathrm{mg}$ every $8 \mathrm{hrs}$ as needed & 10 \\
\hline $10 / 9 / 2018$ & Morphine $2.42 \mathrm{mg}$, PTM $0.1 \mathrm{mg}$ every $8 \mathrm{hrs}$ as needed & 10 \\
\hline $12 / 18 / 2018$ & Hydromorphone $0.38 \mathrm{mg}$ & \\
\hline $12 / 26 / 2018$ & Hydromorphone $0.4181 \mathrm{mg}$, PTM $0.03 \mathrm{mg}$ every $8 \mathrm{hrs}$ as needed & 10 \\
\hline $1 / 8 / 2019$ & Hydromorphone $0.4593 \mathrm{mg}$, PTM $0.03 \mathrm{mg}$ every $8 \mathrm{hrs}$ as needed & 10 \\
\hline $2 / 11 / 2019$ & Hydromorphone $0.5053 \mathrm{mg}$, PTM $0.03 \mathrm{mg}$ every $8 \mathrm{hrs}$ as needed & 10 \\
\hline $3 / 26 / 2019$ & Hydromorphone $0.5563 \mathrm{mg}$, PTM $0.03 \mathrm{mg}$ every $8 \mathrm{hrs}$ as needed & 10 \\
\hline
\end{tabular}

\{AU: Abbreviations: PTM, Patient Therapy Manager?\}

within the epidural space at the L4-5 level, within the right neural foramina, on the right pedicle of the L5 and L4-5 perivertebral regions along with pathological (questionable) areas of enhancement at the T6-T10 vertebral levels. Subsequent to the evaluation and review of the MRI diagnostic images and interpretation with a neurosurgeon, a diagnosis of arachnoiditis was made and the patient started on therapy with high-dose prednisone administration with the intention of therapy targeted at reducing the inflammatory components of the disease process. An additional treatment plan supplement was a decision to substitute morphine with hydromorphone within the IT pump.

In order to accomplish the hydromorphone substitution of IT morphine, the patient was scheduled for a procedure visit at the pain clinic. The port site was prepped and draped in the usual sterile fashion. A 22-gauge noncoring needle was introduced through the skin and into the diaphragm of the IT port. Subsequently, $5.5 \mathrm{~mL}$ of morphine was aspirated from the pump and discarded. The pump was washed out with repeated injections and aspiration of preservative-free normal saline $(10 \mathrm{~mL})$ administered through a filter to ensure proper wash-out of the pump. During the final stage, $40 \mathrm{~mL}$ of hydromorphone $(5 \mathrm{mg} / \mathrm{mL})$ was then injected through the filter with aspiration following every $5 \mathrm{~mL}$ to verify appropriate chamber-filling. The needle was removed, a sterile dressing applied, and the pump reprogrammed at 0.38 mg per day of hydromorphone using a conversion factor of 6:1 with a bridge bolus time of 43 hours.

Following substitution of hydromorphone into the IT pump, the patient reported an approximate $30 \%$ improvement in pain symptoms within just a few days of making the change. However, as the prednisone dose was being tapered, the patient again began to experience and complain of more radicular pain. With these worsening symptoms, the hydromorphone infusion rate was titrated up to $0.5563 \mathrm{mg}$ per day along with the addition of a patient therapy manager (PTM) dose of $0.03 \mathrm{mg}$ every 8 hours as needed. The changes made with increasing the IT hydromorphone along with the PTM dosage resulted in improved pain control while on low-dose oral steroids. The complaints of pain 
radiating into both lower extremities was improved. There is now residual pain related to orthopedic issues of his right hip. A follow-up MRI of the lumbar spine 6 months later continued to indicate similar findings of "mild" arachnoiditis of the nerve roots at the L4 and L5 vertebral levels and slightly more peripherally located within the thecal sac, but without evidence of thecal sac adherence.

\section{DISCUSSION}

In addition to the confirmatory MRI findings, a new onset of radicular pain for the patient in this case report resulted in the diagnosis of arachnoiditis. Of note, the MRI revealed that the L4 and L5 nerve roots were "slightly" peripherally located within the thecal sac and without adherence to the thecal sac. The above findings remain as one of $3 \mathrm{MRI}$ findings that are typically associated with arachnoiditis. According to Ross et al (11), the following criteria identified on MRI are used in the diagnosis of arachnoiditis and include: (a) conglomerations of adherent nerve roots centrally within the thecal sac, (b) nerve roots adherent peripherally to the meninges, and (c) a soft tissue mass replacing the subarachnoid space.

The etiology of arachnoiditis has been attributed to several predisposing factors, including chemical exposure to agents such as antiseptics, contrast media, preservatives, etc.; trauma, infection, medications, degenerative disease, and surgical interventions and procedures (12-14). In this case report, the timing sequence of the patient's symptoms correlated with the continuing up-titration of IT morphine dosage. Morphine has been characterized and determined to play a role in the inflammatory process $(15,16)$. Specifically, morphine can activate mast cells, leading to the release of substance $P$ and tryptase (15), both of which can result in sustained inflammation as well as sensitization of the central nervous system to inflammatory mediators and their effects $(15,16)$.

Since administration of IT morphine was highly suspected as the causal agent of arachnoiditis in the patient described in this case report, a decision was made to substitute the morphine within the pump with IT hydromorphone. According to the 2012 Polyanalgesic Consensus Conference (PACC) guidelines, hydromorphone was suggested as a first-line agent along with morphine for use in IT infusion pumps for treatment of nociceptive pain (17). Hydromorphone was selected to replace the IT morphine due to its equivalent efficacy parameters, its demonstrated safety profile, and lower likelihood of inflammatory reaction(s) when compared to morphine (18). A similar case has been previously reported in which ziconotide, a voltage-gated calcium channel inhibitor and another first-line agent, was substituted for morphine in a patient with IT morphine-induced arachnoiditis $(19,20)$. Ziconotide has been shown to not result in granuloma formation and also considered as an alternative IT agent option (20).

Hydromorphone was chosen over ziconotide for the patient described in this case report secondary to the patient's underlying comorbid disease pain state and the larger nociceptive component of his pain, as opposed to treating the neuropathic symptoms/aspect of pain. It was also determined that this patient's radicular pain symptoms were more iatrogenic and originating from the neuraxial inflammatory response caused by the progressive up-titration of IT morphine administration versus progressive or worsening pain symptoms originating from the patient's underlying disease etiology.

Another factor considered in choosing IT hydromorphone versus ziconotide was the evidence that the patient experienced relief of his pain symptoms during the opioid-based IT trial, suggesting that switching to another opioid (one with an improved side-effect profile) would be more appropriate. In addition, ziconotide has a narrower therapeutic window and is known to be associated with several adverse side effects $(21,22)$. Some of the recurring adverse effects of ziconotide include central nervous system symptoms of mood changes, along with increasing alterations in mental status, both of which occur in a dose- and rate-related manner. Negative psychiatric effects of ziconotide such as confusion, hallucinations, and psychosis have been reported and can limit the use of ziconotide in the chronic pain patient population and in those with psychiatric disease (21).

\section{CONCLUSION}

In summary, we report a rare event of IT morphineassociated arachnoiditis and subsequent management by switching to an alternative IT opiate. In any patient diagnosed with new-onset radicular symptoms along with a recently placed IT pump infusing morphine, it remains reasonable and prudent to screen for a potential case of morphine-induced arachnoiditis. In addition, if other potential causes of arachnoiditis have been ruled out and the IT medication is suspected as the etiology, it is reasonable to substitute the pump infusion agent with an alternative medication. While inflammatory reactions 
from IT morphine are well known and documented, this case report has described the continued successful treatment of a patient's radicular pain by switching the IT drug from morphine to hydromorphone. It is believed that this treatment option is a viable alternative for this particular patient and considered a rational strategy when confronted with IT morphine-induced arachnoiditis.

\section{REFERENCES}

1. Bottros MM, Christo PJ. Current perspectives on intrathecal drug delivery. J Pain Res 2014; 7:615.

2. Bejjani GK, Karim NO, Tzortzidis F. Intrathecal granuloma after implantation of a morphine pump: Case report and review of the literature. Surg Neurol 1997; 48:288-291.

3. Miele VJ, Price KO, Bloomfield S, Hogg J, Bailes JE. A review of intrathecal morphine therapy related granulomas. Eur J Pain 2006; 10:251-261.

4. Wadhwa RK, Shaya MR, Nanda A. Spinal cord compression in a patient with a pain pump for failed back syndrome: A chalk-like precipitate mimicking a spinal cord neoplasm: Case report. Neurosurgery 2006; 58:E387; discussion E387.

5. Cabbell KL, Taren JA, Sagher O. Spinal cord compression by catheter granulomas in high-dose intrathecal morphine therapy: Case report. Neurosurgery 1998; 42:1176-1180

6. Kochany JZ, Sarria JE, Tran ND. Increasing back and radicular pain 2 years following intrathecal pump implantation with review of arachnoiditis. Pain Med 2013; 14:1658-1663.

7. North RB, Cutchis PN, Epstein JA, Long DM. Spinal cord compression complicating subarachnoid infusion of morphine: Case report and laboratory experience. Neurosurgery 1991; 29:778-784.

8. Blount JP, Remley KB, Yue S K, Erickson DL. Intrathecal granuloma complicating chronic spinal infusion of morphine. Report of three cases. J Neurosurg 1996; 84:272-276.

9. Aldrete JA, Vascello LA, Ghaly R, Tomlin D. Paraplegia in a patient with an intrathecal catheter and a spinal cord stimulator. Anesthesiology 1994; 81:1542-1545; discussion 1527A-1528A.

10. Coffey RJ, Burchiel K. Inflammatory mass lesions associated with intrathecal drug infusion catheters: Report and observations on 41 patients. Neurosurgery 2002; 50:78-87.

11. Ross JS, Masaryk TJ, Modic MT, et al. MR imaging of lumbar arachnoiditis. AJR Am J Roentgenol 1987; 149:1025-1032.

12. Kochany JZ, Tran ND, Sarria JE. Increasing back and radicular pain

\section{Acknowledgments}

The authors would like to thank the editors of Pain Medicine Case Reports for their guidance and assistance with this manuscript.
2 years following intrathecal pump implantation with review of arachnoiditis. Pain Med 2013; 14:1658-1663.

13. Koerts G, Rooijakkers H, Abu-Serieh B, Cosnard G, Raftopoulos C. Postoperative spinal adhesive arachnoiditis presenting with hydrocephalus and cauda equina syndrome. Clin Neurol Neurosurg 2008; 110:171-175

14. Abhinav K, Bradley M, Aquilina K, Patel N. Spinal arachnoiditis and cyst formation with subarachnoid haemorrhage. Br J Neurosurg 2012; 26:574-575.

15. Vincent L, Vang D, Nguyen J, et al. Mast cell activation contributes to sickle cell pathobiology and pain in mice. Blood 2013; 122:1853-1862

16. Aich A, Afrin LB, Gupta K. Mast cell-mediated mechanisms of nociception. Int J Mol Sci 2015; 16:29069-29092.

17. Deer TR, Prager J, Levy R, et al. Polyanalgesic Consensus Conference 2012: Recommendations for the management of pain by intrathecal (intraspinal) drug delivery: Report of an interdisciplinary expert panel. Neuromodulation 2012; 15:436-466

18. Johansen MJ, Satterfield WC, Baze WB, Hildebrand KR, Gradert TL, Hassenbusch SJ. Continuous intrathecal infusion of hydromorphone: Safety in the sheep model and clinical implications. Pain Med 2004; 5:14-25.

19. Codipietro L, Maino P. Aseptic arachnoiditis in a patient treated with intrathecal morphine infusion: Symptom resolution on switch to ziconotide. Neuromodulation 2015; 18:217-220; discussion 220 .

20. Pope JE, Deer TR. Ziconotide: A clinical update and pharmacologic review. Expert Opin Pharmacother 2013; 14:957-966.

21. Maier C, Gockel HH, Gruhn K, Gruhn K, Krumova EK, Edel MA. Increased risk of suicide under intrathecal ziconotide treatment? - A warning. Pain 2011; 152:235-237.

22. Sukul VV. Intrathecal pain therapy for the management of chronic noncancer pain. Neurosurg Clin N Am 2019; 30:195-201. 
